\title{
Multi-physics based Simulations of an Oleo-pneumatic Shock Absorber System for PHM
}

\author{
Krishna Lok S. ${ }^{1}$, and Khazi M. M. Siddiqui ${ }^{2}$ \\ ${ }^{1,2}$ CSIR-National Aerospace Laboratories, Bengaluru, Karnataka, 560017, India \\ kls@nal.res.in, khazi.siddiqui@gmail.com
}

\begin{abstract}
The paper presents multi-physics (Mechanical, Thermal, Hydraulic, and Pneumatic) based modelling and simulation of an Oleo-pneumatic shock absorber with fault capabilities. The fault simulated in this model is leakage due to eccentricity. The one-dimensional shock absorber system models to give loads at different sink velocities. These load values, used in the structural model to do static stress analysis. By using these loads directly from the system model eliminates the error in load computation from the load's group, thereby eliminating the time and cost involved in this activity. The models and static stress analyses carried out with both 1-D and 3-D elements. The 3-D landing gear model meshed with using both auto and manual mesh generation options. The consequences of both 1-D and 3-D models mesh generation, discussed in this paper. The static stress analysis, compared with the experimental results and it is found that the results are within 5\% deviation. Based on the static stress and fatigue analysis computed the life of a landing gear.
\end{abstract}

\section{INTRODUCTION}

A tricycle type of landing gear's shock absorber, chosen for the modelling and simulation. In this, both the healthy and fault cases addressed. The simulations include quasi-static and dynamic simulation of a shock absorber system. The shock absorber is an integral part of a landing gear of an aircraft. The first adverse events table, constructed by collecting data gathers from findings within the ASRS (Aviation Safety Reporting System), FAA (Federal Aviation Administration), and NTSB (National Transport Safety Board) databases and shown in Table 1, from reference "Mary, Tolga, Karen, Jeffrey, Colleen (2010)". In this work, slow progression faults related to hydraulic failures being

Krishna Lok et al. This is an open-access article distributed under the terms of the Creative Commons Attribution 3.0 United States License, which permits unrestricted use, distribution, and reproduction in any medium, provided the original author and source are credited. addressed. "Milwitzky, and Cook (1952)" has shown the analysis of Landing-gear behaviour, indicating that the simplified linear segment variation is adequate for tire deflection characteristics and this followed in this paper. "James (1996)" developed a FORTRAN program to model, simulates and validated the results with the experimental data.

Table 1 Integrated Vehicle Health Management (IVHM) Adverse Events

\begin{tabular}{|c|c|}
\hline $\begin{array}{c}\text { Adverse Event } \\
\text { Type }\end{array}$ & Example Damage Condition \\
\hline Incipient faults & $\begin{array}{l}\text { 1. Icing conditions in propulsion } \\
\text { system } \\
\text { 2. Fault of power electronics } \\
\text { 3. Turbine engine bearings }\end{array}$ \\
\hline $\begin{array}{l}\text { Slow progression } \\
\text { faults }\end{array}$ & $\begin{array}{l}\text { 4. Fatigue cracks on metallic airframe } \\
\text { structure } \\
\text { 5. Delamination in composites } \\
\text { 6. Hydraulic failures } \\
\text { 7. Air conditioning and pressurization } \\
\text { faults } \\
\text { 8. Oil and/or lubrication failures }\end{array}$ \\
\hline $\begin{array}{l}\text { Intermittent } \\
\text { faults }\end{array}$ & 9. Wire chafing failures \\
\hline Cascading faults & $\begin{array}{l}\text { 10. Power system faults } \\
\text { 11. Control surface faults (aileron, } \\
\text { rudder, or elevator) } \\
\text { 12. Instrumentation, communication, } \\
\text { and navigation failures } \\
\text { 13. Fuel system faults }\end{array}$ \\
\hline $\begin{array}{l}\text { Fast progression } \\
\text { faults }\end{array}$ & $\begin{array}{l}\text { 14. Engine stall or faults in } \\
\text { turbomachinery } \\
\text { 15. Landing gear faults } \\
\text { 16. Brake and/or anti-skid system } \\
\text { faults } \\
\text { 17. Lightning- and radiation-related } \\
\text { avionics faults }\end{array}$ \\
\hline
\end{tabular}


Prognostics Health Management (PHM) diagnostic approaches, broadly divided into two types: the model-based and data driven as described in "Edward, Abhinav, Sriram, Indranil and Kai (2011)". This work in the paper considers model-based approach. The system modelling and analyses are done in Siemens' Advanced Modelling Environment Simulation (AMESim) software package. It is a multiphysics domain based package to model Mechanical, Hydraulic, Pneumatic, Thermal, Electrical and Electronic Systems and 2-dimensional structures/ bodies. This package based on bond graph theory to model multi-domain components.

"Guoming, Liang, and Meng (2011)" used AMESim and Virtual Lab software packages and "Prashant (2006)" used Finite Element Analysis (FEA), Multi-body simulation using SIMPACK software package. These two references give global overview, different steps, and their link being explained through a flowchart.

In a taxonomy of prognostic approaches with increasing cost and accuracy, the top of the pyramid being occupied by physics-based models as indicated by "Kai, George and Marcos (2013)". The multi-physics models' being on the top of the triangle is presented in this paper show its significance to PHM.

The paper begins with the modelling of a shock absorber system in 1D dynamic simulation software here the authors demonstrate the various (3) levels of modelling with increasing complexities. In section two and three demonstrating the fault (leakage) model of a shock absorber system. In the section four validation of our models done through an experimentation. In section five modelling flexible landing gear in 1D and 3D showing its significance. Computing the force component from 1D system model and incorporating this force component in Finite Element Analysis (FEA) thus demonstrating co-simulation. In the last, the paper ends with concluding remarks about the work being presented.

\section{Physics based Modelling}

Physics-based models use a physical understanding of the system to estimate the remaining useful life of a system. There exist two major challenges in physics based prognostics: 1) the lack of sufficient knowledge on physics of failure degradation and 2) the inability to obtain the values of the parameters in the formulations, as stated by "Eker, Camci, and Jennions (2012)".Modelling of a shock absorber done at different tiers (levels). The first model has lesser number of sub-components. In this, a separate pneumatic chamber/ bottle modelled with or without the tyre or tire model. The second level (tier) model is a detailed model having all the four chambers modelled. The third level is a fault model, modelled with a leakage sub-component.

\subsection{Healthy Model}

The healthy model is real system emulation. The healthy model of an oleo-pneumatic shock absorber is as shown in Fig. 1. The flow rate equation for an orifice is given by Eq. (1).

$$
Q=C_{q} A \sqrt{\frac{2|\Delta p|}{\rho}}
$$

Where

$\mathrm{Q}$ - Flow rate $\left(\mathrm{m}^{3} / \mathrm{s}\right)$

$\mathrm{C}_{\mathrm{q}}$ - Flow coefficient

A - Surface area of opening $\left(\mathrm{m}^{2}\right)$

$\Delta \mathrm{p}$ - Pressure difference $(\mathrm{Pa})$

$\rho$ - Air density $\left(\mathrm{kg} / \mathrm{m}^{3}\right)$

The efficiency or waveform coefficient used to describe how square an output curve is. The efficiency is the ratio of square wave output to actual output force for a given application. To compute the area under the curves as shown in Fig. 2 using MATLAB program (www.mathworks.com) the trapz (xv, yv) function. The efficiency computed using the area under the curve divided by the maximum area. The efficiencies for with and without wheel configurations are 73.333 and 68.071 respectively.

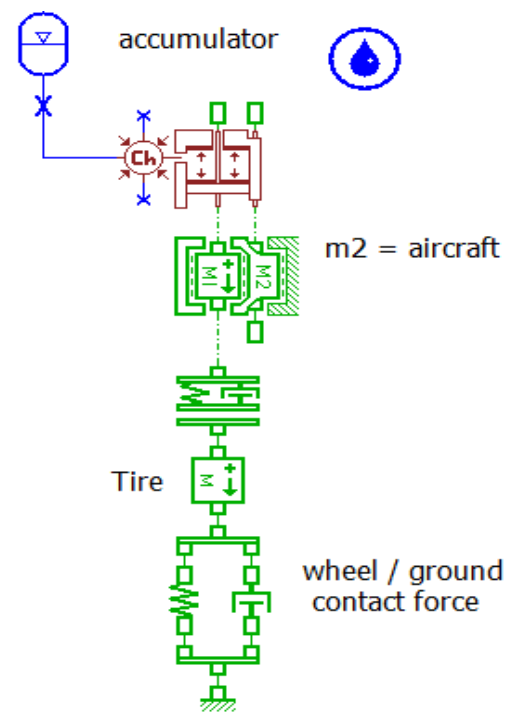

Fig. 1 Level I model of an oleo-pneumatic shock absorber 


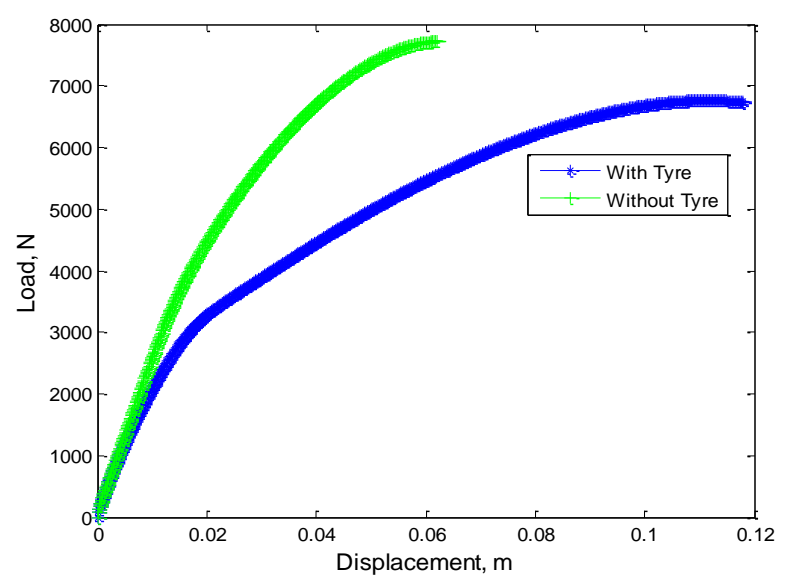

Fig. 2 Efficiencies computation curves

The second level of an oleo-pneumatic shock absorber with its all four chambers is as shown in figure 3 . The various parameters for this model used are given in Table 2. A similar detailed model of a shock absorber with PID controller simulated by "Heininen (2015)" for both static and dynamic cases. In the case of a quasi-static modelling, a ramp load applied whereas in the case of dynamic the vertical drop velocity provided as an input parameter.

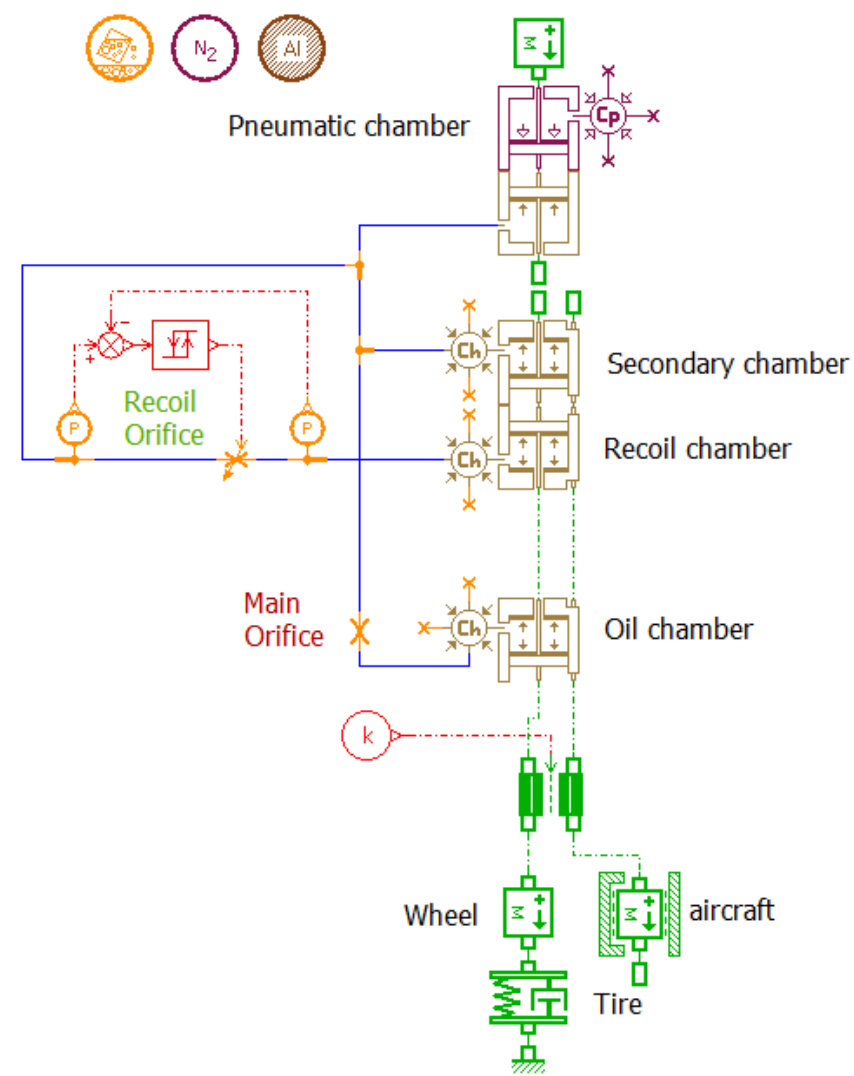

Fig. 3 Level II model of an oleo-pneumatic shock absorber
Table 2 List of various parameters for healthy model

\begin{tabular}{|c|c|c|c|}
\hline $\begin{array}{l}\mathbf{S} \\
\mathbf{N}\end{array}$ & Title & Unit & Value \\
\hline $\mathbf{I}$ & Parameters of aircraft & & \\
\hline 1 & Sprung (Cradle) Mass & $\mathrm{Kg}$ & 1824 \\
\hline 2 & Un-sprung (Wheel) mass & $\mathrm{Kg}$ & 45 \\
\hline 3 & Sink Velocity & $\mathrm{m} / \mathrm{s}$ & 3.05 \\
\hline II & Parameters of chamber & & \\
\hline 4 & Oil chamber piston diameter & $\mathrm{mm}$ & 80 \\
\hline 5 & $\begin{array}{l}\text { Secondary chamber piston } \\
\text { diameter }\end{array}$ & $\mathrm{mm}$ & 60 \\
\hline 6 & $\begin{array}{l}\text { Recoil chamber piston } \\
\text { diameter }\end{array}$ & $\mathrm{mm}$ & 15 \\
\hline 7 & $\begin{array}{l}\text { Pneumatic chamber piston } \\
\text { diameter }\end{array}$ & $\mathrm{mm}$ & 105 \\
\hline 8 & Pressure & Bar & 13.6 \\
\hline 9 & $\begin{array}{l}\text { Pneumatic chamber dead } \\
\text { volume }\end{array}$ & $\mathrm{L}$ & 0.2 \\
\hline III & Parameters of main orifice & & \\
\hline 10 & Equivalent orifice diameter & $\mathrm{mm}$ & 9.5 \\
\hline 11 & Maximum flow coefficient & Null & 0.64 \\
\hline IV & Parameters of Recoil orifice & & \\
\hline 12 & Equivalent orifice diameter & $\mathrm{mm}$ & 6 \\
\hline 13 & Maximum flow coefficient & Null & 0.64 \\
\hline $\mathbf{V}$ & $\begin{array}{l}\text { Parameters of spring } \\
\text { damper }\end{array}$ & & \\
\hline 14 & Spring rate & $\mathrm{N} / \mathrm{m}$ & $25 \mathrm{E} 4$ \\
\hline 15 & Damper rating & $\mathrm{N} /(\mathrm{m} / \mathrm{s})$ & 15000 \\
\hline
\end{tabular}

\subsection{Fault Model}

Once the healthy model built and checked for its complete performance, described in section 4, now for the Prognostic Health Monitoring and Management require fault model. A healthy model has no provision for fault inception, whereas an unhealthy model has fault or degradation capability built into the model.

The unhealthy/ fault model built using sub-component which cater for fault simulation as in fig. 4 (the leakage sub-model part) or this simulated by changing the parameters. The latter one is simple to do but the former requires a subcomponent level model built-in the software. If not, the user has to build a custom component that suits the requirement. 
The leakage part component introduced in the place of a recoil chamber (Fig. 4) is the novelty of this paper. The leakage component fault parameters are given in Table 3 . The leakage flow rate equation is given by Eq. 2 this is more complex compared to Eq. 1. The unhealthy behaviour is modelled with a leakage component which has the feasibility to model leakage with variable length, eccentricity and viscous friction. This component used for the recoil chamber part. The shock absorber shown here is to model the leakage in the recoil chamber which is a common type of fault observed in most of the shock absorbers. Fig. 4 depicts a model of an oleo-pneumatic shock absorber which has mechanical, thermal, pneumatic and hydraulic capabilities built-in. There are four chambers one pneumatic and remaining three are hydraulic. In this model, there is a provision to incorporate sensors like displacement, accelerometer and pressure sensors at numerous locations, as described by "Wlamir and Joao (2014)". One typical location is as shown in Fig. 4.

A systematic methodology for the design of a Prognostic Health Management system should include a means for selecting and combining a set of data-to-information (sensors) conversion tools to convert machine data into performance-related information to provide health indicators/indices for decision makers to effectively understand the current performance and make maintenance decisions before potential failures occur, presented in "Lee, Fangji, Wenyu, Masoud, Linxia, David (2013)".

$$
Q=-\frac{\Delta p}{12 \mu l_{c}} r_{c}^{3} \pi d_{p}\left[1+\frac{3}{2}\left(\frac{e c c}{r_{c}}\right)^{2}\right]+\frac{v^{+}-v^{-}}{2} r_{c} \pi d_{p}
$$

Where

$\Delta \mathrm{p}$ - pressure difference between port 2 and port $1: \mathrm{p}_{2}-\mathrm{p}_{1}$

$\mathrm{r}_{\mathrm{c}}$ - radial clearance defined as, $\mathrm{r}_{\mathrm{c}}=\mathrm{d}_{\mathrm{c}} / 2$

$\mathrm{d}_{\mathrm{p}}$ - external piston diameter

$1_{c}-$ contact length obtained

$\mu$ - fluid dynamic viscosity taken at mean pressure

ecc - eccenctricity

$\mathrm{v}+$ and $\mathrm{v}$ - correspond respectively to the velocities of the cylinder (envelop) and the piston

\section{Dynamic Simulations}

The dynamic simulation (interval of 2 seconds) for the cases of healthy and fault models. The temperature variation is almost six times in the pneumatic chamber compared to that of a hydraulic chamber. The graph representing this temperature variation being shown in Fig. 5.

Table 3 Parameters of a fault model

\begin{tabular}{llll}
\hline S N & Description & Unit & Value \\
\hline 1 & $\begin{array}{l}\text { Piston } \\
\text { diameter }\end{array}$ & $\mathrm{mm}$ & 15 \\
2 & $\begin{array}{l}\text { Clearance } \\
\text { diameter }\end{array}$ & $\mathrm{mm}$ & 0.2 \\
3 & Contact length & $\mathrm{mm}$ & 30 \\
\hline
\end{tabular}

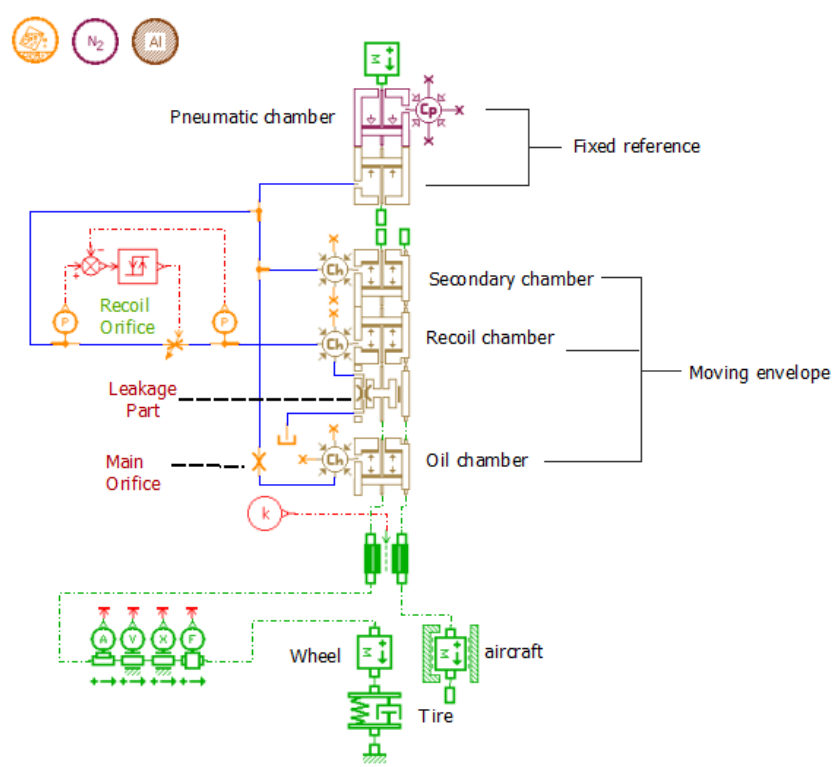

Fig. 4 Level III fault simulator model of shock absorber

The leakage introduction represents the fault model of an oleo-pneumatic shock absorber of an aircraft. Here the leakage model presented with an external orifice provided for the leakage sub-component. The leakage orifice diameter is $1.5 \mathrm{~mm}$. The graph shows that the displacement destabilizes the aircraft. The diverging phenomenon seen due to leakage is as shown in figure 6 .

A dynamic simulation carried out for the healthy model. The various sink velocities considered are $1,2,3.05$, and $4 \mathrm{~m} / \mathrm{s}$. The third velocity $3.05 \mathrm{~m} / \mathrm{s}$ corresponds to $10 \mathrm{ft} / \mathrm{sec}$ this is the maximum allowed sink velocity as per the Federal Aviation Regulations (FAR). The loads obtained from these simulations results, input into the structural model. This process of load computation eliminates the error in load computation. The magnitude of the load is an important factor. Here the load magnitude is one direction only. In the case of lateral drift landing all three $\mathrm{x}, \mathrm{y}$, and $\mathrm{z}$ components 
of loading exist. The loading in all three directions viz., the vertical, drag, and side load happens in a lateral drift landing case as described in the report by "Krishna, Pulak, and Satish (2012)". The resultant magnitude is important. The various magnitudes of vertical force for different sink velocities are shown in Fig. 7.

\section{EXPERIMENTAL VERIFICATION}

The experimental drop test results being compared with the simulated healthy multi-physics based model. The experimental and simulated comparison curves for the displacement, vertical force, and pressure being shown in figures 8, 9, and 10 respectively. They do show a good comparison. The vertical force comparison is similar to that shown by "Cai-Jun, Yu, Wen-Gang, and Jian-Hua (2012)".

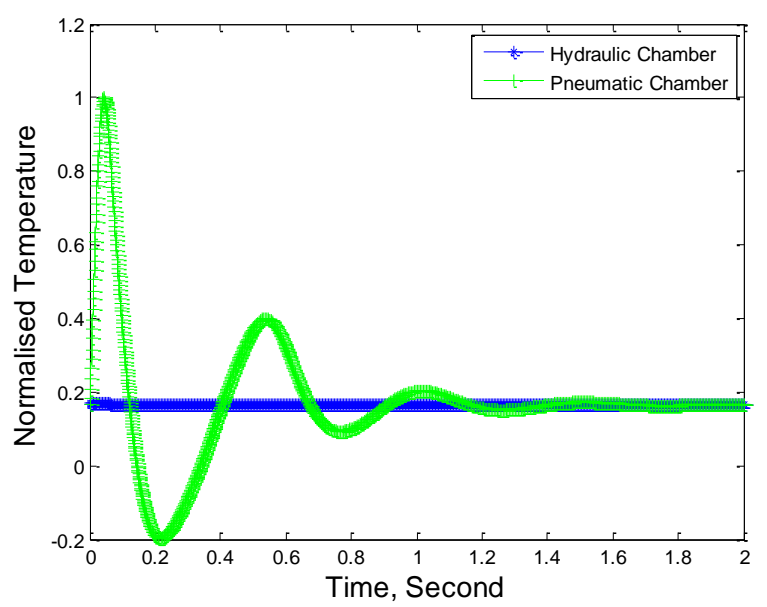

Fig. 5 Variation of temperature in two chambers

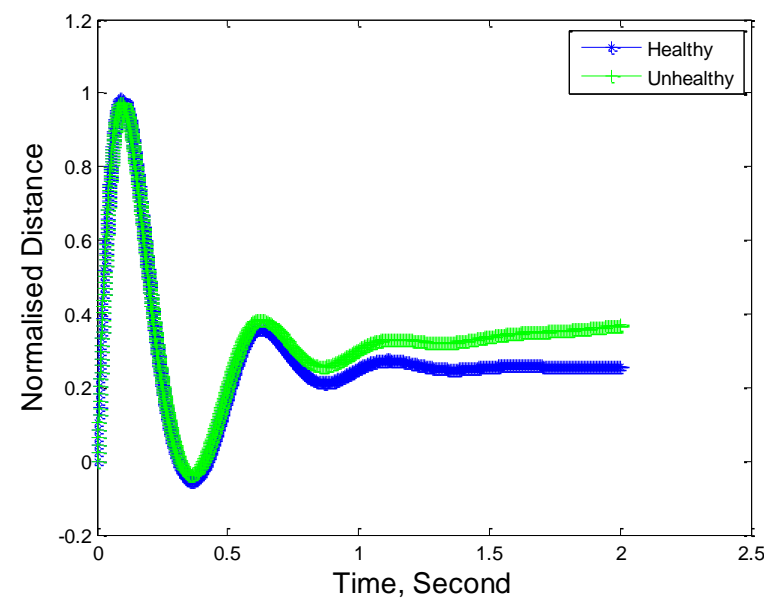

Fig. 6 Aircraft displacement for different conditions

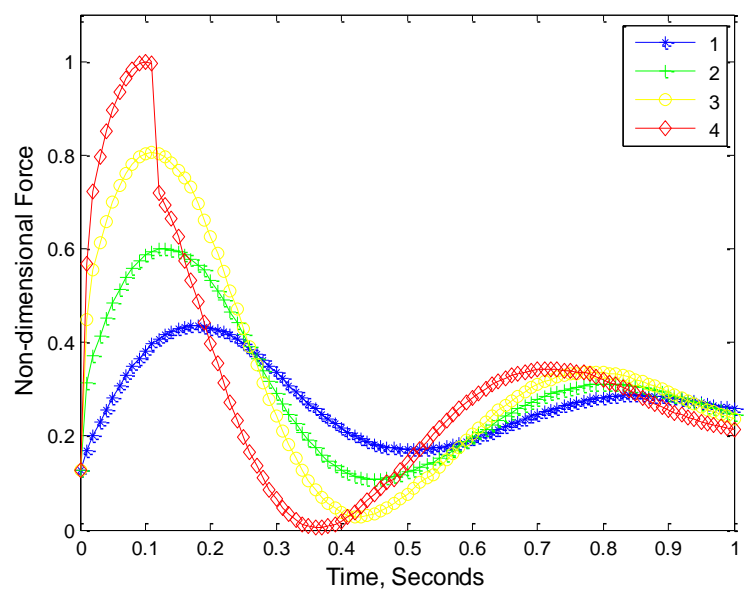

Fig. 7 Vertical force magnitudes for various sink velocities

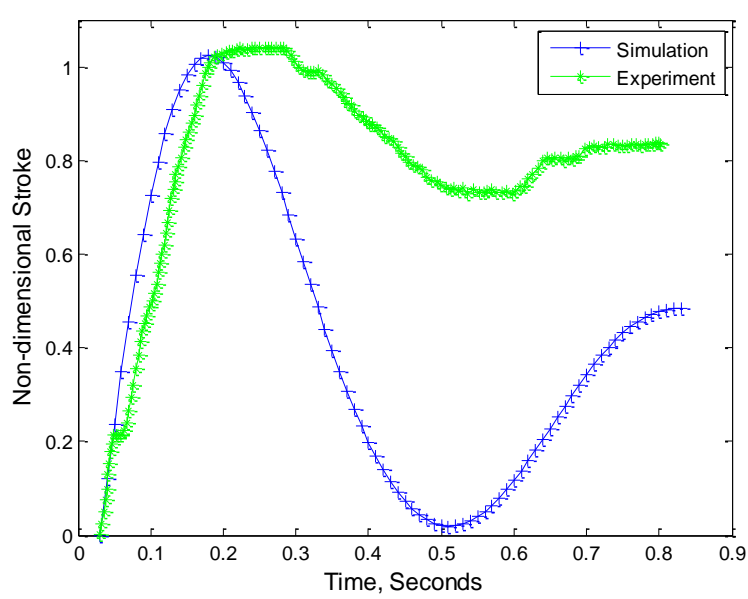

Fig. 8 Shock absorber stroke displacement versus time 


\section{Co-simulation}

Co-simulation is the combination of system and structural analysis being presented in this section. The output force magnitude from the physics-based model is input to the structural model. The structural model of landing gear made up of two materials their properties are indicated in Table 4. Aluminum is the material for upper and lower toggle links and the remaining part of the structure is of Steel material. For the structural modelling of landing gears has been done using CATIA. The meshing part is done using Hypermesh package (www.altair-india.in) and analysis in Abaqus. The fundamental static finite element equation is given in Eq. 3.

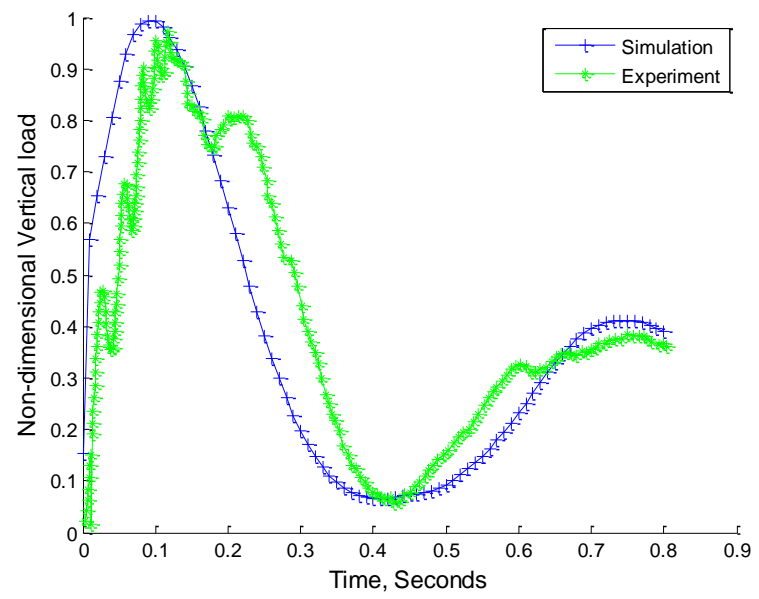

Fig. 9 Comparison curves for vertical load versus time data

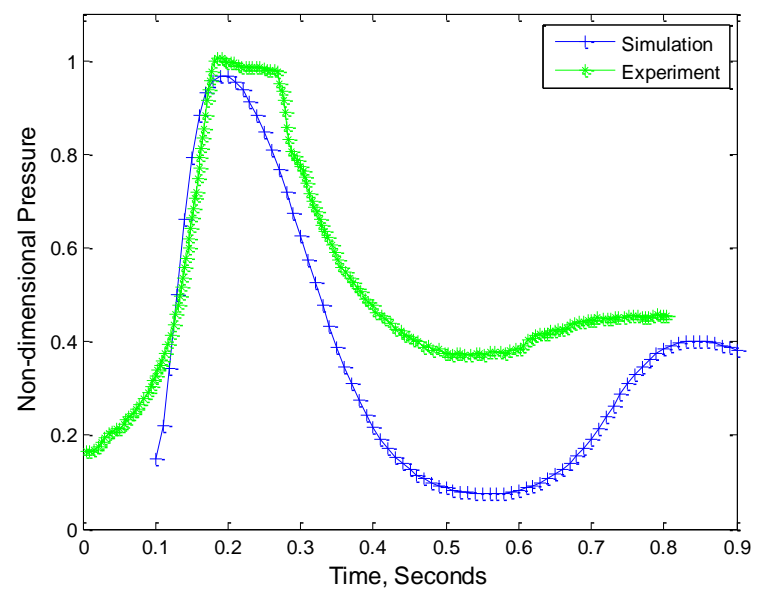

Fig. 10 Comparison curves for pressure versus time data

$$
[K]\{q\}=\{f\}
$$

Where, $[\mathrm{K}]$ - global stiffness matrix

$\{\mathrm{q}\}$ - global nodal displacement vector

$\{f\}$ - global nodal force vector
Table 4 Material properties for landing gear

\begin{tabular}{llll}
\hline S N & Description & Steel & Aluminum \\
\hline 1 & Modulus of elasticity (GPa) & 210 & 72 \\
2 & Poisson ratio & 0.25 & 0.3 \\
3 & $\begin{array}{l}\text { Ultimate tensile strength } \\
\text { (MPa) }\end{array}$ & 1230 & 480 \\
\hline
\end{tabular}

\subsection{One-dimensional model}

The one-dimensional structural model with beam elements of a Nose landing gear is as shown in figure 11. The various beam profiles considered for the gear has been listed in Table 5.

Table 5 Beam pipe section profiles and their dimensions

\begin{tabular}{llll}
\hline \multirow{2}{*}{$\mathrm{S} \mathrm{N}$} & \multirow{2}{*}{ Component } & \multicolumn{2}{l}{ Beam cross-section profiles } \\
\cline { 3 - 4 } & & Radius, mm & Thickness, mm \\
\hline 1 & Cylinder & 57.5 & 9.5 \\
2 & Piston & 39.55 & 5.0 \\
3 & Stub-axle & 49 & 9.5 \\
4 & Actuator & 22.15 & 5.6 \\
5 & Pintel Pin & 25.5 & 7.0 \\
6 & Yoke & 30.0 & 5.0 \\
7 & Axle & 25.5 & 7.0 \\
\hline
\end{tabular}

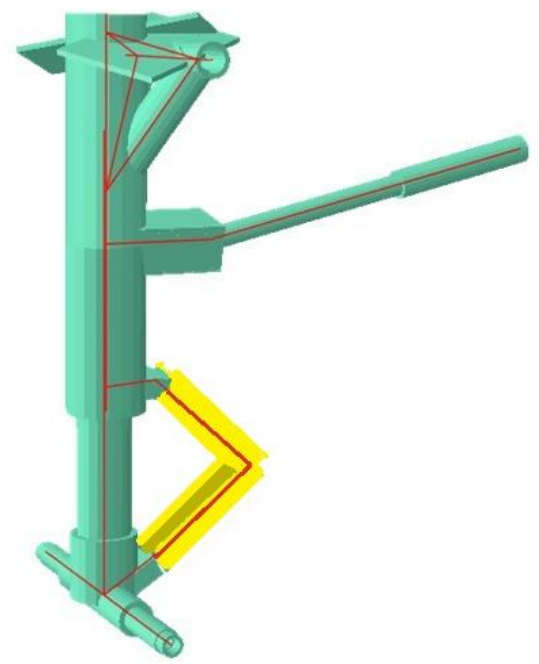

Fig.11 One-dimensional superimposed with beam profile

\subsection{Three-dimensional model}

A three-dimensional (3D) model of a nose landing gear's nomenclature, mesh, boundary conditions (BC), and loading has been shown in figure 12. A typical auto mesh model has tetrahedral elements the number of nodes 47995 and elements as 163364 whereas the manual mesh has a number 
of nodes 291321 and hexa-8, tria-3, and tetrahedral elements as 595 753. Observed that the manual mesh has more than three times that of the auto mesh's number of nodes and elements. In our earlier paper by "Krishna and Abdul (2014)" the stress and fatigue analysis results were presented.

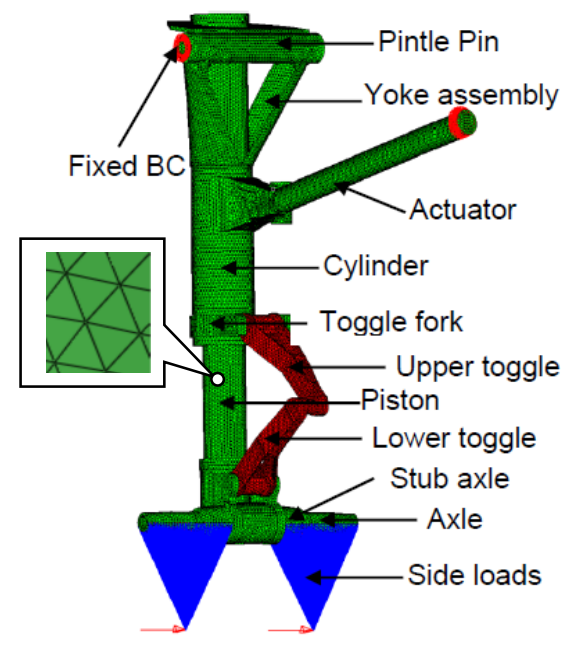

Fig.12 Nomenclature, FE model, BCs, Material, and Loads

A comparison of displacement and stress magnitudes are given in Table 6 for one (1D) and three dimension (3D) models at different sink velocities. Corresponding to the sink velocity of $3.05 \mathrm{~m} / \mathrm{s}$ case, the stress contour plot shown in Fig. 13 for 1D case. From the stress analysis output, the maximum stress value computed the landing gear (LG) life as IE6 cycles using the S-N approach. This indicates that the LG has 1 million cycles of life.

Table 6 Stress magnitudes for different sink velocities

\begin{tabular}{|c|c|c|c|c|c|}
\hline \multirow{2}{*}{$\begin{array}{l}\text { Sink } \\
\text { velocity } \\
(\mathrm{m} / \mathrm{s})\end{array}$} & \multirow{2}{*}{$\begin{array}{l}\text { Vertical } \\
\text { force } \\
\text { (N) }\end{array}$} & \multicolumn{2}{|c|}{$\begin{array}{l}\text { Displacement } \\
(\mathrm{mm})\end{array}$} & \multicolumn{2}{|c|}{$\begin{array}{l}\text { von-Mises stress } \\
(\mathrm{MPa})\end{array}$} \\
\hline & & $1 \mathrm{D}$ & $3 \mathrm{D}$ & $1 \mathrm{D}$ & $3 \mathrm{D}$ \\
\hline 1 & 9073 & 0.357 & 0.321 & 67.14 & 68.39 \\
\hline 2 & 12608 & 0.496 & 0.459 & 93.30 & 94.97 \\
\hline 3.05 & 17060 & 0.670 & 0.603 & 126.20 & 128.60 \\
\hline 4 & 21304 & 0.838 & 0.753 & 157.60 & 160.50 \\
\hline
\end{tabular}

\section{Concluding Remarks}

The work presents the three levels of multi-physics models based simulation of an oleo-pneumatic shock absorber for a typical aircraft for PHM.
Demonstrated the leakage phenomenon modelling for an oleo-pneumatic shock absorber along with its equation.

As we have now advanced packages for simulation, it is essential to do thorough modelling and simulation of the complete LG with various models. Arrive at the optimum

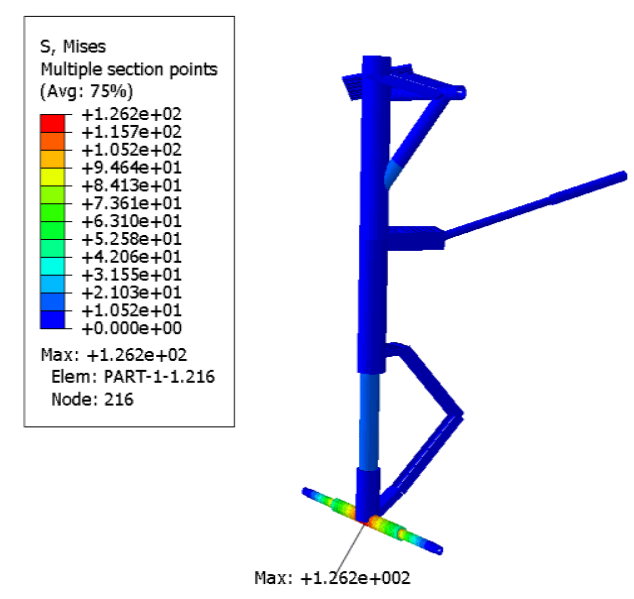

Fig. 13 Stress contours on a Nose Landing Gear

configuration. Earlier due to the lack of advanced software packages, not much of the models' development and emphasis not given. The lesson learned is now our design has to be for manufacture and maintainability.

One and three-dimensional landing gears stress models render stress magnitude values within the maximum deviation of 2 percent.

From the static stress analysis, observed that axle and toggle links are the most critical components.

Using the co-simulation (system and structure) concept the load computation errors get minimized.

For the considered loading cases computed the life of a nose landing gear.

Future work planned is to work closely with the industry with the usage of powerful software packages, developing the best landing gear for future generation aircraft.

\section{ACKNOWLEDGEMENT}

Authors acknowledge the support rendered by Mr Shyam Chetty Director, CSIR-NAL, Dr Satish Chandra, Head and M \& A, S T T D, Dr Harinarayana K, Former Director, ADA, Mr Subba Rao M., Former Head, ACD and Dr G. Prathap, Former Director, CSIR-NISCAIR. Authors do acknowledge all those who directly or indirectly contributed to this work. 


\section{REFERENCES}

Arttu Heininen (2015), Modelling and Simulation of an Aircraft Main Landing Gear Shock Absorber, Master of Science Thesis, pp 1-67, Tampere University of Technology, Master's Degree Programme in Mechanical Engg.

Cai-Jun X, Yu H, Wen-Gang Q, and Jian-Hua D, (2012) Landing-Gear Drop-Test Rig Development and Application for Light Airplanes, Journal of Aircraft, Vol. 49, No. 6, November-December 2012, DOI: 10.2514/1.C031913

Edward B, Abhinav S, Sriram N, Indranil R, and Kai G, (2011) Experimental Validation of a Prognostic Health Management System for Electro-Mechanical Actuators, Infotech@Aerospace, 29-31 March 2011, AIAA 20111518.

Eker O F, Camci F, and Jennions I K (2012) Major Challenges in Prognostics: Study on Benchmarking Prognostics Datasets, European Conference of Prognostics and Health Management Society 2012.

Federal Aviation Regulations (FAR) part 25, Airworthiness Standards Transport Category Airplanes, May 2009 Edition.

Guoming Ji, Liang Zhang, and Meng Dong (2011) Dynamic Simulation on retraction \extension system of an aircraft, Xi' an China, 978-1-4577-0536-6/11, 2011 IEEE, 39393944.

James N Daniels, (1996) A Method for Landing Gear Modeling and Simulation with Experimental validation, NASA Contractor Report 201601, June 1996.

Kai Goebel, George Vachtsevanos and Marcos E. Orchard, in Chapter 4: Prognostics of Integrated Vehicle Health Management the Technology, 2013 SAE international http://books.sae.org ISBN 978-0-7680-7952-4, edited by Ian K. Jennions.

Krishna Lok S and Abdul Waheed A (2014), Stress and Fatigue Damage Computation of a Nose Landing Gear, Int. J. Fracture \& Damage Mechanics 1-10, Journal Pub, vol. 2 Issue 1.

Krishna Lok Singh, Pulak Chakrabarti, Satish Chandra, Report on Computation of NLG and MLG Landing Loads, NCAD/DQ-04/0005/2012, 21March 2012.

Lee J, Fangji Wu, Wenyu Zhao, Masoud Ghaffari, Linxia Liao, David Siegel (2013), Prognostics and Health Management Design for Rotary Machinery Systems Reviews, Methodology and Applications, Mech. Syst. Signal Process. http://dx.doi.org/10.1016/j. ymssp.2013.06.004.

Mary S R, Tolga K, Karen M L, Jeffrey L B, Colleen A W (2010), Assessment of the State of the Art of Integrated Vehicle Health Management Technologies as Applicable to Damage Conditions, National Aeronautics and Space Administration (NASA), Glenn Research Center, Cleveland, Ohio 44135, NASA/TM-2010-216911
Milwitzky B, and Cook F E, (1952) Analysis of Landing-gear Behavior, NACA TN 2755, Washington D C.

Prashant Dilip Khapane, (2006) Simulation of Landing Gear Dynamics and Brake-Gear Interaction, Dissertation, 1125, DLR-German Aerospace Center.

Wlamir O. L. Vianna, Joao Pedro P. Malere, (2014) Aircraft Hydraulic System Leakage Detection and Servicing Recomendedations Method, Annual Conference of the Prognostics and Health Management Society.

\section{BIOGRAPHIES}

Krishna Lok S. is a Principal Scientist at CSIR-National Aerospace Laboratories. He has a B.E. in Mechanical Engineering from University Visvesvaraya College of Engineering and master's from M. S. Ramaiah Institute of Technology, Bangalore. He has a Ph. D., in "Fracture Mechanics based Assessment of Embedded Delamination in Laminated Composites" from Aerospace Engineering Department, Indian Institute of Science, Bangalore, Karnataka, India. He has a vast experience as a researcher for about 15 years. He has 15 Journal, 39 Conference papers, delivered Guest Lectures. His team awarded best technical paper presentation in the year 2014, LMS Indian Aerospace \& Defense User Conference. His research interest includes Solid Mechanics, Composites and Metallic Materials, Finite Element Analyses, Fatigue of Structures \& Materials, Fracture Mechanics, Testing (Material Characterization and Structural Components), Structures and Systems Health Monitoring and Management. Awarded Sir C V Raman Research Fellowship, worked at IVHM Center, Cranfield University, UK, with Prof. Ian Jennions and Dr Zakwan Skaf.

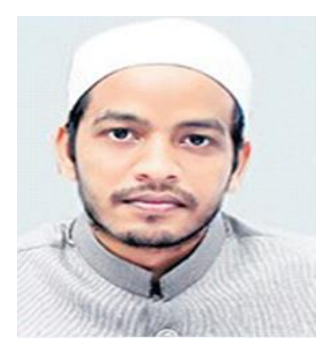

Khazi M. M. Siddiqui was born in Nandyala, India, in 1988. He received the $\mathrm{B}$. Tech., degree in Mechanical Engineering from the University of Jawaharlal Nehru Technological University (JNTU), Anantapur, India, in 2010. In 2011, he joined as a Trainee Engineer, Hindustan Aeronautics Limited (HAL), Bengaluru, India. In 2013 he joined CCE-Proficiency course on Structural Analysis and Design Optimization of Mechanical Systems, Indian Institute of Science (IISc), Bengaluru, India. In 2014, he joined M. Tech., degree in Machine design from the University of Visvesvaraya Technological University (VTU), Belagavi, India, In 2015 did his academic Internship and continued to do project work at Council of Scientific and Industrial Research-National Aerospace Laboratories (CSIR-NAL), Bengaluru. 